\title{
Empirical evidence of a long-run relationship between agriculture and manufacturing industry output in Nigeria
}

\author{
Eze Simpson Osuagwu* \\ Department of Economics and Development Studies \\ Covenant University, Ota Nigeria \\ E-mail: eze.osuagwu@ covenantuniversity.edu.ng \\ Telephone: +2348033214346
}

*International Institute for Development Studies, Wilmington DE 19802 United States.

Center for the Study of Development Economics, Nigeria.

Research assistance provided by Emmanuella Uzoamaka at Covenant University, Ota Nigeria

\begin{abstract}
This study investigates a relationship between agriculture and manufacturing industry output in Nigeria from 1982-2015, using the Granger causality, co-integration and error correction techniques. Empirical evidence reveals a bidirectional relationship between the sectors. Although, a positive and significant relationship exists in the short and long-run estimates, a long-run divergence from the vector error correction model suggest that changes in agricultural productivity are not restored to equilibrium, given that macroeconomic factors distort the linkage. Policy implications indicate that macroeconomic stability is a necessary condition for agricultural and manufacturing sectors to foster economic growth.
\end{abstract}

Keywords: Agriculture; Manufacturing Industry; Granger Causality test, Co-integration; Vector Error Correction model;

JEL Classification Code: C22, N17, O13, O14 


\section{Introduction}

The oil boom of the 1970's caused the neglect of agriculture and manufacturing sectors in favor of an unhealthy dependence on crude oil in Nigeria. Although endowed with abundant agro-resources and ecological diversity, Nigeria has become a significant food importer in sub-Saharan Africa. Although, indications from recent studies show that there is a decline in agriculture compared to manufactured goods trade for today's developing countries (Desai and Rudra, 2018), Nigeria has neither improved its agriculture nor improved manufacturing for export. No doubt, successful developing countries have pursued an exportled growth agenda to earn the much-needed foreign exchange for a strong domestic economy. There is a fervent need to transform the Nigerian economy to a rapidly growing economy with sustained and inclusive development, to this end, strategies to foster economic growth must include a clear understanding of the interaction between agriculture and manufacturing industry in order to create jobs, and ultimately reduce poverty. The linkage between agriculture and industry has been a long-debated issue in the development literature (Saikia, 2009). This instant study investigates a long-run relationship between agriculture and manufacturing industry output in Nigeria using Granger Causality test, Co-integration and Error Correction Model, on a time series data from 1982 to 2015. The time frame for this study is limited by data constraints.

Improving the agricultural sector is a necessary condition for food security tackling the risks associated with agrarian intensification, especially for climate-smart agricultural practices. Overall, agricultural efficiency presents essential opportunities for climate change mitigation and adaptation while increasing agricultural productivity and dealing with the issue of food security, unemployment, and poverty. Some scholars have argued that the transformation from agriculture to industry is a movement from traditional to modern, Zeira and Zoabi (2015) contends that rising productivity of modern sectors drives economic growth, however, this claim is on the assumption of a rising marginal opportunity costs in the desire to create new modern sectors. In the same vein, Diao, McMillan, and Wangwe (2018) finds a positive correlation between labour productivity growth in agriculture and employment in the manufacturing sector in Africa. The study demonstrates that positive technological change in agriculture feeds into increasing productivity and growth of the industrial sector.

Nigeria is facing an imminent food security crisis, increasing poverty levels, high unemployment with a growing population, which depends mainly on imported food. Despite Nigeria's significant resource endowments, there is sporadic economic growth; poverty remains widespread since the late 1990s. Agriculture employs approximately two-thirds of the country's total labor force and contributing 40 percent to Nigeria's GDP (IFAD 2012). Nigeria is the world's largest producer of cassava, yam, and cowpeas; yet it is a food-deficit nation and depends on the import of food. Most of the rural population farm on a subsistence scale, using small plots and depending on seasonal rainfall. The lack of infrastructure such as roads and irrigation to mention but a few, further exacerbates poverty in rural areas by isolating rural farmers from inputs and profitable markets. Pressure from growing population impacts already diminished resources, further threatening food production. Over-farmed land, deforestation, and overgrazing are severe in many parts of the country. Drought has become common in the North, while erosion and flooding are problems in the South.

Studies reviewed on this subject for Nigeria focus on government providing infrastructure and credit facilities to improve the agricultural sector, none has delved into an 
empirical investigation of the linkage between agriculture and manufacturing industry productivity; since agriculture provides necessary input for manufacturing industries. The policy objective for this study is to determine a veritable channel for government expenditure towards increasing agricultural proceeds needed for industrial development or investing in industrial production for manufactured goods to aid agricultural productivity. Econometric tests reveal a bidirectional relationship between agriculture and manufacturing industry output, but the vector error correction specification diverges in the long-run, which arguably could be attributed to the behavior of macroeconomic variables. Policy implications uncover a need for macroeconomic stability as a necessary condition for a long-run convergence in the linkage between agriculture and manufacturing industry output. This study is presented in five sections, the second is a review of relevant literature, and the third is the theoretical framework and methodology, the fourth section presents the empirical analysis and discusses the findings of the study, while the study concludes in the fifth section.

\section{Literature Review}

A large body of literature discusses the synergy between agricultural output and industrial productivity in economic development. The institutional debates leave a hollow on the role of agriculture in economic growth and industrialization, especially for developing countries (Osuagwu \& Olaifa, 2018). It is believed in some quarters that improved agriculture will provide the necessary raw material for industries to thrive, but the other side of the discussion views increased agricultural productivity as a result of technical progress driven by industrial innovation. Either way, agriculture and industrialization seem to be strongly interdependent because agriculture does not only supply inputs needed in agro-based industries but utilizes industrial outputs such as pesticides and farm equipment. The literature, therefore, seems very diverse.

Lin and Koo (1990) investigates the relationship between China's agricultural and industrial sectors from 1952 to 1988, the findings reveal that growth in the agricultural sector contributes to the growth of the industrial sector, but the converse is not true. This implies a unidirectional causality. One primary reason that may be proffered for a unidirectional relationship in this case is the Chinese adoption of Soviet-styled economic development strategy, where industrialization is overly emphasized as a government policy at the expense of agriculture. A pervasive feature of developing country development strategy is the "urban bias" policy, which places less emphasis on the agricultural sector, especially for young school leavers eager to be employed in administrative and service positions rather than on the farm. In contrast to the findings in Lin and Koo (1990), Koo and Lou (1997), finds a significant relationship at 5\% between agricultural growth and industrial income, but the agricultural income variable is not significant in the growth model, which implies that industrial growth contributes to agricultural growth, but agricultural growth does not contribute to increasing industrial productivity. A significant reason for the different results may be due to progress in the economic development of the Chinese economy and the diminishing role of agricultural sector.

In the argument, whether labour productivity in the agricultural sector has any significant effect on industrialization in Africa, Diao et al. (2018) posit that the synergy

between labor productivity in agriculture and industrial sector signifies only a necessary but not sufficient condition for improvements in industrialization. The link between rural income through agriculture and the demand for manufactured goods in Africa account for why increases in agricultural labor productivity could lead to positive changes in employment in 
agro-based manufacturing. Suffice to say that agriculture provides the raw material for the industrial sector; but industrial machines are needed for extraction, which imbues a bidirectional causality on the relationship between the sectors. The process of agroindustrialization leads to employment opportunities, improvement in the creation of income and increased earning for farmers. This makes it possible for the employed to purchase necessary food items and increase available food for the economy. Also, as agricultural productivity increases, export increases thereby improving the balance of payment, increasing foreign reserve and stabilizing the exchange rate. However, this could be achieved only with the provision of necessary infrastructure that supports the development of agriculture such as road, transport, water, credit, rural electrification, and a competitive market structure, coupled with the human capacity, which includes policy-makers, researchers, farmers, entrepreneurs and extension workers.

Omorogiuwa et al. (2014), stated that there is an inverse relationship between agricultural productivity, outputs, and food importation. Furthermore, the study reveals that the oil boom of the 1970's and 80's in Nigeria resulted in a boost of the manufacturing sector and a high incidence of rural-urban migration, leading to neglect of the agricultural sector and an increase in food importation, which further impoverished the rural farmer. Nevertheless, some of the rural farmers who had acquired education left the farm for employment in the manufacturing industries, which hitherto led to the neglect of the agricultural sector and the decline in the supply of raw material for use in the agro-based manufacturing sector. The need to fill this shortfall with imported raw material leads to pressure on the foreign reserve resulting in a depreciation of the local currency and high inflation on the price of manufactured goods. To this end, Nigeria is not favorably disposed to embrace the transition from agriculture to industrialization, and as a result, suffer immensely from the unbalanced effect on economic development. Another argument in this direction is the lack of government support to peasant farmers through improved social protection policies (Osabohien and Osuagwu, 2017). Also, the environmental degradation in the Niger Delta region due to oil exploitation, resulting in low agricultural yield and the outright disenchantment of individuals engaged in farming in these communities (Osuagwu and Olaifa, 2018)

Subramaniam and Reed (2009) examined agricultural inter-sectoral linkages and its contribution to economic growth in transition countries. The study estimates an econometric model, which incorporates linkage between agriculture, manufacturing, service and trade sectors using a vector error correction model and the Johansen procedure of co-integration analysis to identify the existence of long-run and dynamic short-run inter-sectoral linkages. The study concludes that there are definite links between agricultural productivity and industrialization. This positive linkage leads to higher productivity in the use of resources and sustainable economic growth. The analysis shows that the higher demand for processed food will stimulate the economy in several ways. First, the higher demand will attract more local and international food processing firms. Second, it will stimulate the macroeconomy for growth. However, Desai and Rudra (2018) is of the opinion that most developing countries are transitioning from traditional agriculture and moving up the value-added chain towards processed agriculture, providing raw material for firms with global production and distribution systems, and hence increasing the vulnerability of the rural population excluded from the higher value-added agriculture.

Ogundari and Awokuse (2016) investigates the effect of agricultural productivity on different food security measures in Sub-Saharan Africa (SSA), finds that increasing 
agricultural productivity leads to sustainable food security. Food security indicators were per capita food available in tonnes and per capita nutrient supply, while agriculture value added per hectare and cereal production per hectare measures agricultural productivity. A balanced panel data for the period 1980 to 2009 on 41 Sub-Saharan African (SSA) countries was used for the empirical analysis. The empirical results from both the dynamic and linear models show that irrespective of the choice of food security indicator considered, agricultural productivity had a positive impact on the level of food security in the study area. This result suggests that an improvement in SSA agricultural productivity is crucial in alleviating the problems of food insecurity. The paper went further to unequivocally support the role of improved agricultural productivity in reducing food insecurity, but stating the major challenge in SSA's agricultural sector as sustained agricultural productivity. Fugile and Roda (2013) argue for sustained agricultural productivity to be achieved, policy measures that start with the dissemination of agricultural technologies and practices to farmers should be established and investment in research and development encouraged.

O'Rayani and Miller (2003) examine the role of Agriculture in poverty alleviation, Income distribution and economic development for Chile economy to understanding the role of agriculture in industrial development. The study examines the impact of agriculture and agro-industrial sectors on poverty and income distribution - an increase in agricultural production, agro-industrial production, and industrial production are simulated. An increase is obtained through either Increasing total productivity or a price subsidy for the sector's products. The study concludes that agriculture and agro-industrial sectors are essential to alleviate poverty. Furthermore, an increase in labour productivity in agriculture has a higher impact on the decline of poverty incidence than an increase in the industrial sector.

A historical account of differences in economic development among nations stipulates uneven rainfall pattern and high temperatures as a primary cause of low productivity in agriculture for sub-Saharan Africa. There is evidence of not more than three months of heavy rainfall during rainy season, sporadic showers and hot dry season for the remaining months of the year (see Acemoglu and Robinson, 2012). For agriculture to thrive, there must be favorable climatic conditions, although technical progress increases the possibility for productivity in agriculture to increase irrespective of geographical misfortune. De Souza (2015) estimates the relationship between the growth rate of agricultural productivity and the manufacturing sector for 62 developing countries using average temperature to indicate changes in agricultural productivity. The study reveals that a percentage increase in agriculture raises manufacturing output growth between 0.47 and 0.56 percent in the general specification and between 0.28 and 0.47 percent for the parsimonious estimates. The paper is a significant part of the growing body of literature using climate variations to support changes (shocks) in agricultural output.

In addition to time series and instrumental variable techniques that have been used by authors to estimate reverse causality and omitted variable bias in agricultural development and industrialization, many studies have applied co-integration and error correction models to estimate long-run relationships. There are country-specific studies with mixed results, which includes Gemmell et al. (2000) for Malaysia - findings reveal that manufacturing output and productivity were exogenous in the Granger sense to increases in agriculture. On the other hand, Kanwar (2000) and Chebbi and Lachaal (2007) found a positive response in India and Tunisia, also using a sample of 85 countries for a panel co-integration Tiffin and Irz (2006) confirmed positive response for the majority of countries in the sample. 
In line with some of the studies discussed above, this paper employs the Granger causality test, co-integration and error correction model to investigate the relationship between agriculture and manufacturing industry output for the Nigerian economy.

\section{Theoretical Framework and Methodology}

\subsection{Theoretical Framework}

This study is rooted in Hirschman's theory of unbalanced growth because it accounts for the forward and backward linkages that is associated with agriculture and industry relationship. The Hirschman (1958) theory postulates an unbalanced growth theory, arising from specific common characteristics exhibited by developing countries, such as low levels of Gross National Income (GNI) per capita, slow growth of GNI per capita, substantial inequality and widespread poverty, low levels of productivity, high dependence on agriculture, a backward industrial structure, weak consumption and low savings, high rate of population growth, high dependency ratio, high levels of underemployment and unemployment, technological backwardness and existence of both the traditional and modern sectors (dualism). Also, there exists inadequate infrastructure to harness the available resources, and lack of entrepreneurs and investors to channel the cash flow through the sectors for balanced economic growth. To this end, Hirschman proposed a deliberate unbalanced economic development strategy to maintain the existing structural imbalance, viz., complementarity, external economies and induced investment.

Hirschman unbalanced growth theory is based on the specific needs for investment in strategic sectors of the economy and hence could be related to the Nigerian situation. Instead of pursuing growth in all the sectors at the same time, investments should be prioritized based on comparative advantage, prospective yield and percentage contribution to national income. Agriculture has a potential for generating increasing levels of productivity and proceeds could fuel the industrial sector for sustainable growth and development. However, since the theory assumes that sectors would automatically develop themselves through the linkages effect, the concept of Hirschman's backward and forward linkage becomes very relevant. Following this theory, agricultural productivity will increase if and only if the industrial sector has a backward linkage with the agriculture sector by providing inputs and technologies. On the other hand, the agricultural sector will have a forward linkage with the industrial sector by providing raw materials for manufacturing and processing.

\subsection{Analytical Framework}

The illustration below shows the channel of the existing relationship between agro-industrial linkage and food security. Accelerating economic growth creates income-earning opportunities for the poor. Bhagwati and Srnivasan (2002) call this approach the indirect route while the World Bank refers to it as "broad-based economic growth." The diagram below is the poverty-alleviation cum growth approach.

The illustration shows that industrial growth would have an ultimate impact on poverty reduction through two different routes. The first is through sectoral growth which leads directly to accelerated GDP growth would have a direct impact on income, consumption and employment and, ultimately impact the living standards of the poor, growth-induced effects. The second link is through the expansion of intra-and inter-sector 
linkages; both backward and forward linkage types of the industrial sector, particularly the industry-agriculture which will in the long-run cause a linkage-induced income and employment generation as industrial growth accelerates (Takahiro, Mayumi, \& Tatsufumi, 2006). From the illustration below, favorable external conditions such as multilateral support for industrial and agricultural growth leads to growth in various sectors of the economy through investment in physical capital and employment generation.

\section{Figure 1: Poverty alleviation and the interlinkage of agriculture and industry}

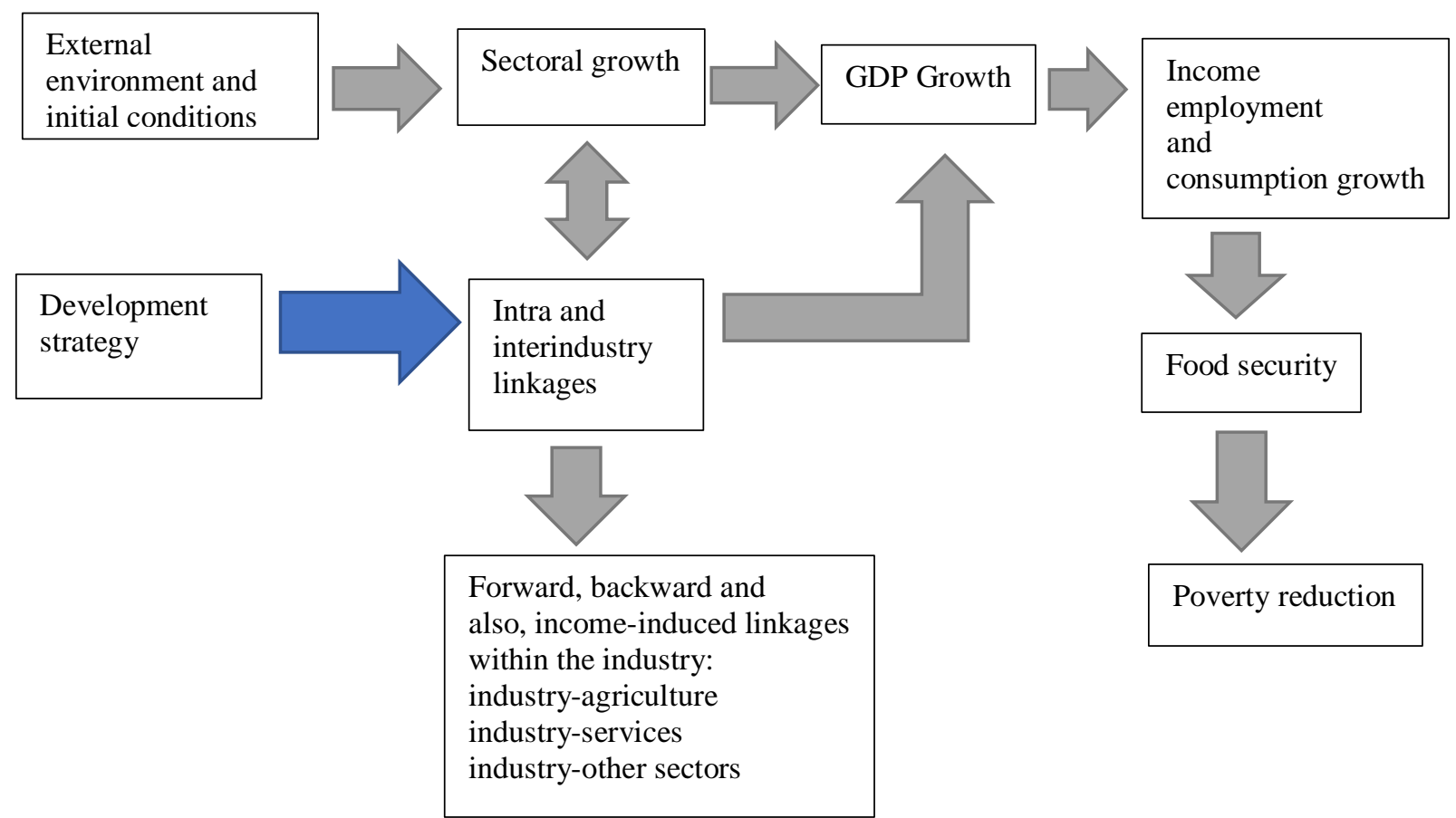

\subsection{Methodology}

\subsubsection{Data}

The data for this study spans the period 1981 to 2015, although constrained by availability, information for the period of study was obtained from Central Intelligence Agency (CIA) World Factbook, Central Bank of Nigeria (CBN) Statistical Bulletin and World Bank Development Indicator. The data for Agriculture value added and Industry value added is obtained from World Bank Development Indicator; government recurrent expenditure on agriculture, commercial bank loans and advances to the agriculture sector and official exchange of the local currency to the US dollar were sourced from the CBN statistical bulletin, while the consumer price index for inflation rate obtained from the CIA World Factbook. 


\subsubsection{Model Specification}

The model for estimation draws from a non-linear production function.

$y=f(X)$

Where $y$ represents agriculture, value added (annual \% growth) used as a proxy for the level of agricultural output in the economy, while $X$ represents all other variables that affect agricultural output.

The implicit model specified as:

$A G R O U T=f(I N F, I N D O T, G R E C A, S C L A, E X C R T)$

Where:

AGROUT is agriculture value added used as a proxy for the level of agricultural output. $I N F$ is inflation rate, consumer prices (annual \%).

INDOT is industry value added which stands as a proxy for changes in industrial output. GRECA is the total government recurrent expenditure on agriculture.

$S C L A$ is the sectoral distribution of commercial banks' loans and advances to agriculture as a proxy for agricultural finance.

EXCRT is the exchange rate of the Nigerian Naira to the dollar

The model specified in its explicit form:

$A G R O U T=\beta_{0}+\beta_{1} I N F+\beta_{2} I N D O T+\beta_{3} G R E C A+\beta_{4} S C L A+\beta_{5} E X C R T+U_{t}$

Where $U_{t}$ is the error term.

From equation (3), the relationship and functional form of the model specified are nonlinear. To transform equation (3) into a log-linear form, we take the second log of the equation.

$\ln$ AGROUT $_{t}=\beta_{0}+\ln \beta_{1} I N F_{t}+\ln \beta_{2} I N D O T_{t}+\ln \beta_{3} G R E C A_{t}+\ln \beta_{4} S C L A_{t}+$ $\ln \beta_{5} E X C R T_{t}+U_{t}$

$$
a \beta_{1}<0, \beta_{2}>0, \beta_{3}>0, \quad \beta_{4}>0, \text { and } \beta_{5}>0 \text { or } \beta_{5}<0
$$

Where $\mathrm{t}=1,2, \ldots \mathrm{n}$ which is the time frame for the variables, $\beta_{0}$ is the intercept term, $\beta_{1}, \beta_{2}, \beta_{3}, \beta_{4}$, and $\beta_{5}$, are the elasticity of AGROUT with respect to INF, INDOT, GRECA, $S C L A$, and EXCRT respectively which also measures the percentage change in AGROUT. $U_{t}$ is the error term, normally distributed with zero mean and constant variance

\subsubsection{Estimation Technique}

Granger causality test is carried out to evaluate the link between agriculture and industrial manufacturing sector. This study applies the Johansen co-integration method in the analysis of the long-run relationship. Co-integration technique is an improvement on the ordinary least square (OLS) method because the co-integration method takes consideration of the nonstationarity associated with time series data (Granger and Newbold, 1974). Non-stationarity implies that the variables do not have a mean that is constant over time. In this study, the 
focus is to determine a long run relationship between agricultural output and explanatory variables.

Granger causality test is a statistical hypothesis test that shows a causal relationship between two variables in a time series. Variable $X$ is said to Granger-cause variable $Y$, if the current value of $Y(y t)$ is conditional on the past values of $X(x t-1, x t-2, \ldots, x 0)$ and thus the history of $X$ is likely to help predict $Y$ (Granger, 1969). This study is to estimate the causal relationship between agriculture and manufacturing industry in order to provide evidence for industrial sector leading to increase in agricultural productivity and if the agricultural sector has caused an increase in manufacturing industry output. Proxy variables are used to measure the industrial sector contribution and agriculture sector contribution.

The equation is hence specified as follows:

$I N D O T=\beta_{0}+\sum \beta_{1} I N D O T_{t-1}+\sum \beta 2 A G R O U T+U_{t}$

AGROUT $=\beta_{0}+\sum \beta 1$ AGROUT $_{t-1}+\sum \beta 2 I N D O T+U_{t}$

A unit root test is conducted to test for stationarity or non-stationarity in a time series. Various tests that can be carried out to determine if the time series data has a unit root, they include: the Kwiatkowski-Phillips-Schmidt-Shin (KPSS), Dickey-Fuller, Augmented DickeyFuller (ADF) and the Phillips-Perron test. The ADF test will be used in this study because it takes into consideration the fact that the error term may be correlated. If a time series is found to be stationary, it could be differenced to the first difference or second difference to make it stationary. If a time series data is stationary at levels, then it is said to be integrated of order 0 denoted by $\mathrm{I}(0)$, if it is differenced once to make it stationary then it is denoted by $\mathrm{I}(1)$ and so on.

The co-integration test is used to determine if there is a long run relationship among the variables in the model. Co-integration ensures that the linear combination of variables is stationary while regression analysis based on time series data discretely assumes all values to be stationary which may not always be the case. The regression of a non-stationary time series data will lead to spurious (nonsense) regression thereby misleading results. A regression whose variables are co-integrated is called a co-integrating regression and the parameters obtained are called co-integrating parameters. This study employs the Johansen (1991) co-integration test.

A Vector Error Correction Model (VECM) applied for data where the underlying variables have a long-run stochastic trend, is also known as co-integration. It is useful for estimating both the short-term and long-term effects of a time series on another. VECM also estimates the speed at which a dependent variable returns to equilibrium after a change in other variables. Economic theory expects the coefficient of the ECM to be negative and significant because it implies that errors generated in each period correctly adjust in subsequent years. The higher the coefficient of the ECM, the higher the speed of adjustment from the short-run to the long-run. Also, when t-stat is greater than 2, the speed of adjustment is assumed to be significant. 


\section{Empirical Analysis and Discussion of Results.}

\subsection{Empirical Analysis}

The first step is to conduct a unit root test for all the variables to test for the stationarity of the variables, which is a necessary condition for understanding the long-run behavior of variables. In carrying out this test, Augmented-Dickey Fuller test is applied. The rule of thumb is that if absolute value of ADF test statistic is greater than McKinnon critical value at $5 \%$, then we reject the null-hypothesis that the variable is non-stationary. The variable is deemed stationary when the absolute value of the ADF statistics test is greater than the critical value at $5 \%$.

Table 1: Unit root test at levels

\begin{tabular}{llllll}
\hline VARIABLES & $\begin{array}{l}\text { LAG } \\
\text { LENGTH }\end{array}$ & $\begin{array}{l}\text { ADF TEST } \\
\text { STATISTICS } \\
\text { AT LEVELS }\end{array}$ & $\begin{array}{l}\text { CRITICAL } \\
\text { VALUE } \\
(5 \%)\end{array}$ & $\begin{array}{l}\text { ORDER } \\
\text { INTEGRATION }\end{array}$ & OFEMARKS \\
\hline LAGROUT & 0 & 0.234840 & -2.954021 & None & Non-stationary \\
LINF & 0 & -3.052959 & -2.954021 & I(0) & Stationary \\
LINDOT & 0 & -0.72591 & -2.954021 & None & Non-Stationary \\
LGRECA & 0 & -2.079774 & -2.960411 & None & Non-Stationary \\
LSCLA & 0 & 0.318118 & -2.954021 & None & Non-Stationary \\
LEXCRT & 0 & -2.212044 & -2.954021 & None & Non-Stationary \\
\hline
\end{tabular}

Source: computed by the author using e-views 9

Table 2: Unit root test at first difference

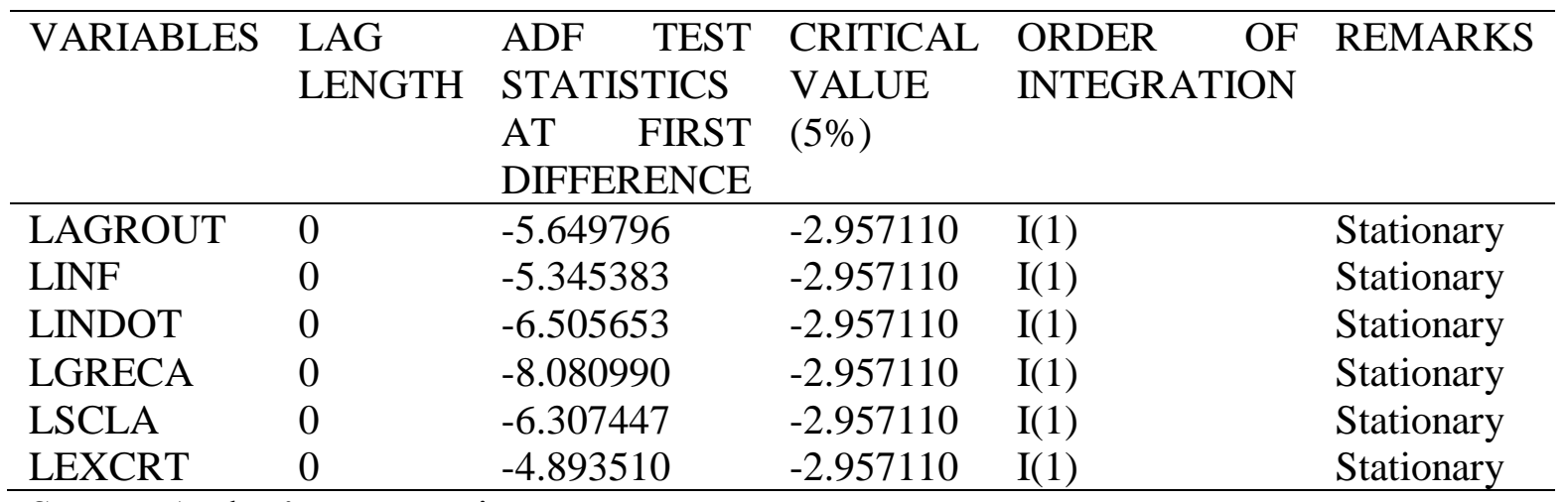

Source: Author's computation

From the table 1, all the variables are non-stationary at levels except LINF, which is stationary at levels $\mathrm{I}(0)$. In order to make all variables stationary at the same level, the test is run on the first difference, thereby making all variables stationary at order I (1) (see Table 2). In absolute terms, the ADF test statistics is greater than the critical value at 5\%. Therefore, the variables are stationary at first difference. Co-integration requires all the variables to be integrated of the same order.

The next step is a co-integration test using the Johansen technique to ascertain the long-run relationship between the dependent variable (LAGROUT) and the independent variables (LINF, LINDOT, LGRECA, LSCLA and LEXCRT). The decision rule states that if the values of trace statistics or maximum Eigen value are greater than the critical values at $5 \%$ 
then the null hypothesis of no co-integration is rejected, which depicts co-integration among variables implying a long-run equilibrium relationship. 
Table 3: Unrestricted Co-integration Rank Test (Trace)

\begin{tabular}{lllll}
\hline \hline $\begin{array}{l}\text { Hypothesized } \\
\text { No. of CE(s) }\end{array}$ & Eigenvalue & $\begin{array}{l}\text { Trace } \\
\text { Statistic }\end{array}$ & \multicolumn{2}{l}{$\begin{array}{l}\text { Critical Value } \\
\text { Prob.** }\end{array}$} \\
\hline None * & 0.732306 & 107.3412 & 95.75366 & 0.0063 \\
At most 1 & 0.696403 & 65.16806 & 69.81889 & 0.1111 \\
At most 2 & 0.407370 & 27.02236 & 47.85613 & 0.8534 \\
At most 3 & 0.198666 & 10.28042 & 29.79707 & 0.9759 \\
At most 4 & 0.088622 & 3.193151 & 15.49471 & 0.9574 \\
At most 5 & 0.006964 & 0.223618 & 3.841466 & 0.6363
\end{tabular}

Trace test indicates 1 co-integrating equation(s) at the 0.05 level

Table 4: Unrestricted Co-integration Rank Test (Maximum Eigenvalue)

\begin{tabular}{lllll}
$\begin{array}{l}\text { Hypothesized } \\
\text { No. of CE(s) }\end{array}$ & Eigenvalue & $\begin{array}{l}\text { Max-Eigen } \\
\text { Statistic }\end{array}$ & $\begin{array}{l}0.05 \\
\text { Critical Value }\end{array}$ & Prob.** \\
\hline None * & 0.732306 & 42.17315 & 40.07757 & 0.0286 \\
At most 1 * & 0.696403 & 38.14570 & 33.87687 & 0.0145 \\
At most 2 & 0.407370 & 16.74194 & 27.58434 & 0.6022 \\
At most 3 & 0.198666 & 7.087273 & 21.13162 & 0.9504 \\
At most 4 & 0.088622 & 2.969533 & 14.26460 & 0.9488 \\
At most 5 & 0.006964 & 0.223618 & 3.841466 & 0.6363 \\
\hline
\end{tabular}

Max-eigenvalue test indicates 2 co-integrating equation(s) at the 0.05 level.

From the table, we can see that under the hypothesized no. of $\mathrm{CE}(\mathrm{s})$, at none*, the value of the trace statistics is greater than the critical value at $5 \%$. From Table 3, we can see that under the hypothesized no. of $\mathrm{CE}(\mathrm{s})$, at none*, the value of the trace statistic is greater than the critical value at $5 \%$. Therefore, we conclude that there is one co-integrating equation, meaning there is a long run relationship between the dependent variable and one cointegrating explanatory variables. Also, from Table 4, the maximum eigenvalue test, the Max-Eigen statistics at most 1 is greater than the critical value at $5 \%$. Thereby concluding that using the Max-Eigen test, there is a long-run relationship between the dependent variable and two co-integrating equations.

Table 5: Normalized co-integrating coefficients

\begin{tabular}{llllll}
\hline LAGROUT & LINF & LINDOT & LGRECA & LSCLA & LEXCRT \\
\hline 1.000000 & $-0.193483^{* *}$ & $-2.553767 * *$ & $-0.695047^{* *}$ & -0.028796 & $1.246587 * *$ \\
& $(0.07419)$ & $(0.45151)$ & $(0.10656)$ & $(0.10651)$ & $(0.14732)$ \\
\hline
\end{tabular}

Standard errors in parenthesis.

**Significant @ 5\%

The normalized co-integrating co-efficient is written in its implicit form, to make it explicit. It is re-written by changing the signs as follow:

$L A G R O U T=0.193 L I N F+2.554 L I N D O T+0.695 L G R E C A+0.029 L S C L A-$ 
The above results in equation 7 , show that there is a positive relationship between inflation rate and agricultural output in Nigeria. A $1 \%$ increase in inflation rate will lead to a $0.193 \%$ increase in agricultural output, ceteris paribus. Theoretically, this ought not to be, an increase in price level is expected to increase the cost of production thereby affecting output level but can be attributed to the structure of the Nigeria economy and the data used in carrying out the analysis.

Also, we see a positive and significant relationship between the proxy of industrial output and agricultural sector, indicating a $1 \%$ increase in industrial output will lead to a $2.554 \%$ increase in agricultural output, ceteris paribus. This is theoretically expected as an increase in industrial output through the backward linkage supported by the Hirschman's unbalanced growth theory will lead to an increase in agricultural output.

The result shows a positive relationship between government recurrent expenditure on the agricultural sector in Nigeria and agricultural output. A $1 \%$ increase in the government recurrent expenditure in the agriculture sector will lead to a $0.695 \%$ increase in the agricultural output, ceteris paribus. This is supported theoretically as an increase in investment or government expenditure leads to improved performance or growth.

There is a positive relationship between the sectorial distribution of commercial loans and advances to agriculture and the agricultural output. A $1 \%$ increase in sectoral distribution of commercial bank loans and advances to agriculture will lead to a $0.029 \%$ increase in agricultural output, holding all other variables constant. One of the major factors that boost the productivity of farmers is access to loans, therefore an increase in loans and advances will boost output.

Also, in the long run, there is a negative relationship between agricultural output and the exchange rate in Nigeria. A $1 \%$ increase in the exchange rate will lead to a $1.247 \%$ decrease in agricultural output, ceteris paribus. This means that for agricultural output to increase, there is a need for a stable and favorable exchange rate. The more the local currency devalues to the dollar, the more the increase in prices thereby affecting production level.

Table 6 below presents the result of a Vector Error Correction Model (VECM); the error correction mechanism (ECM) developed by Engle and Granger is a means of reconciling the short-run behavior of an economic variable with its long-run behavior (Gujarati, 2004). The ECM must lie between 0 and 1 and is expected to be negative. A negative sign indicates a move back towards equilibrium while a positive value indicates a movement away from equilibrium. The error correction model is also known as a speed of adjustment factor which tells how fast the system will adjust to restore equilibrium.

Table 6: vector error correction model results

\begin{tabular}{ll}
\hline Error Correction: & D(LAGROT) \\
\hline CointEq1 & $\begin{array}{l}0.029258^{* *} \\
(0.00840)\end{array}$ \\
D(LAGROUT(-1)) & -0.342095 \\
& $(0.18971)$ \\
D(LINF(-1)) & $0.070813^{* *}$ \\
& $(0.02256)$ \\
D(LINDOT(-1)) & $0.542231^{* *}$ \\
& $(0.24817)$ \\
D(LGRECA $(-1))$ & -0.010076
\end{tabular}




\begin{tabular}{lc} 
& $(0.01894)$ \\
D(LSCLA(-1)) & 0.005417 \\
& $(0.02929)$ \\
D(LEXCRT(-1)) & $\begin{array}{c}-0.152893 * * \\
(0.06698)\end{array}$ \\
& \\
C & 0.115535 \\
& $(0.02467)$ \\
\hline R-squared & 0.721003 \\
Adj. R-squared & 0.507652 \\
F-statistic & 3.379420
\end{tabular}

Standard error in ( ) parenthesis, **Significant @5\%

The error correction coefficient tells us the speed at which our model returns or converges to equilibrium after an exogenous shock. As a result, the error correction term should be negatively signed to indicate a move towards long run equilibrium. The co-efficient of the error correction term in Table 6 has positive, but significant values. Therefore, we can say that the error correction term, in the long run, will diverge or move away from equilibrium. The adjustment speed is 0.0292 which implies that in the long-run given any initial shock with a speed of adjustment of $2.92 \%$ the error term diverges.

Taking the first difference of the lagged dependent variable, the error correction estimate for inflation, industrial output and sectoral distribution of loans and advances $\{\mathrm{D}(\operatorname{LINF}(-1))$, D(LINDOT(-1)), and D(LSCLA(-1)) \} respectively as explanatory variables indicate that the model diverges in the long-run given any initial shock with a speed of adjustment of $7.08 \%$, $54.22 \%$, and $0.54 \%$ respectively. The error correction estimate for government expenditure on the agricultural sector and exchange rate of the Naira to the dollar $\{$ D(LGRECA(-1)) $\}$ and $\{\mathrm{D}($ LEXCRT(-1)) $\}$ indicate that the equation converges in the long run given any initial shock with a speed adjustment of $1.00 \%$, and $15.2 \%$ respectively.

The existence of a relationship between variables does not imply or prove a causality nor a direction of influence (Gujarati, 2004). The Granger causality test looks at how variable $X$ can affect variable $Y$. Granger (1969) approach to the question of whether $x$ causes $y$ is to see how much of the current $y$ can be explained by past values of $y$ and then to see whether adding lagged values of $x$ can improve the explanation; $y$ is said to be Granger-caused by $x$ if $x$ helps in the prediction of $y$, or equivalently if the coefficient on the lagged $x$ 's is statistically significant. A further test is carried out in this study to find out if there is a bidirectional relationship between the dependent variable agricultural output (LAGROUT) and the independent variable, industrial output (LINDOT). This is done to know if there is an interlinkage between the agricultural sector and industrial sector in Nigeria. The rule of thumb is that if the probability value is greater than $5 \%$, we fail to reject the null hypothesis of no bidirectional relationship.

Table 7: Pairwise Granger causality tests

\begin{tabular}{llllll}
\hline \hline Null Hypothesis: & & & Obs & F-StatisticProb. \\
\hline \hline $\begin{array}{l}\text { LINDOT does } \\
\text { LAGROUT }\end{array}$ & not & Granger & Cause & & \\
LAn & & & & 3.39421 & 0.0484
\end{tabular}


From table 7, we see that the probability value of LINDOT does not Granger Cause LAGROUT is $4.84 \%$ and the probability value of LAGROUT does not Granger Cause LINDOT is $0.54 \%$. Following the rule of thumb, we, therefore, reject the null hypothesis. This means that there is a bidirectional relationship between the agricultural sector and industrial sector in Nigeria.

Lastly, we use the Ordinary Least Squares (OLS) results in Table 8 to test for the short run dynamics; the results of the OLS estimate is used to ascertain the behavior of the variables in the absence of the co-integration or error correction mechanism.

Table 8: Ordinary Least Squares (OLS) regression analysis

\begin{tabular}{ll}
\hline Variable & Coefficient \\
\hline \hline LINF & $\begin{array}{l}-0.019 \\
(0.035) \\
1.719 * * \\
(0.227)\end{array}$ \\
LINDOT & 0.031 \\
& $(0.042)$ \\
LGRECA & 0.022 \\
& $(0.041)$ \\
LSCLA & -0.050 \\
& $(0.063)$ \\
LEXCRT & 0.963 \\
& 0.956 \\
\hline \hline R-squared & 145.855 \\
Adjusted R-squared & \\
S.E. of regression & 0.134 \\
F-statistic & 0.000 \\
Prob(F-statistic) & \\
\hline \hline
\end{tabular}

** Significant at 5\%. Standard error in parenthesis

In the short run, we observe that the only significant explanatory variable from Table 8 is industrial output. This implies that there is a positive relationship between agricultural output and industrial output even in the short run. The statistical evidence shows that a 1 percent increase or change in industrial output gives rise to a $1.7 \%$ change in agricultural output, ceteris paribus. This corroborates the finding in the vector error correction estimate, although the magnitude of change differs but the direction is the same.

\subsection{Discussion of Results}

The empirical result of the Granger Causality test in Table 7, shows that there is a bidirectional relationship between agricultural productivity and industrial output in favor of the interlinkage hypothesis, this finding corroborates the result in Gemmel et al. (2000) for the Malaysian economy, but contradicts Koo and Lou (1997) for a unidirectional causality 
between agriculture income and manufacturing productivity in post-communist China. In developing countries, many industries are agro-based, given that agricultural produce are largely used as raw material for manufacturing. On the other hand, use of manufactured goods by agro and allied outlets increases the tendency of linkage between agriculture and manufacturing industry interaction (Diao et al. 2018). In the short run estimate, we see a positive and significant relationship between agriculture and manufacturing industry output, which supports the observation of many of the sampled countries in Tiffin and Irz (2006). However, this result is typical for developing countries as stated in Kanwar (2000) and Chebbi and Lachal (2007). In advanced economies where, agriculture is highly mechanized, industrial output seems to be relatively divergent into several sectoral inputs, with a meager but significant contribution to the growth of agriculture, except measured explicitly for agrobased industries.

From Table 6, the vector error correction coefficient is positive which shows that in the longrun, our model diverges from equilibrium given that all the lagged explanatory variables are subject to differing, but unique behavior. In the normalized co-integration estimation (see Table 4) there is a positive relationship between agricultural productivity and manufacturing industry output supporting the result in the vector error correction model, which also corroborates the short-run dynamics. This evidence denotes that the behavior of our dependent variable concerning the explanatory variables did not change over time; both in the long-run and short-run. However, this observation is subject to the conditions that other explanatory variables are held constant in the estimation. Nevertheless, the positive relationship between agriculture and industrialization is supported in the literature by Subramaniam and Reed (2009), where a robust inter-sectorial linkage is found using the vector error correction model and Johansen co-integration procedure. In the same vein, Ogundari and Awokuse (2016) found a similar result for the level of food security indicators and agricultural productivity for sub-Saharan Africa countries. Worthy of note is that in the transformation from agrarian to industrial manufacturing, economies are expected to conquer the menace of hunger. To this end, industrialization connotes an unparalleled food sufficiency for the teeming population. Food sufficiency, on the other hand, requires improved technical know-how for agricultural productivity. The positive interplay of agriculture and industry is a necessary condition for improved economic growth and development.

Overall, in the short-run, the only significant variable that would explain changes in agricultural productivity is industrial output, with a positive coefficient. All other explanatory variables were insignificant in the short-run model. However, the normalized co-integration and vector error correction estimates show similar results for all explanatory variables except government expenditure on agriculture with a positive sign in the normalized co-integrating estimate and negative for the long-run effect. However, inflation rate did not follow a priori expectation in both the short and long-run model. This may be due to the fact that inflation is largely dependent on the exchange rate in Nigeria because of the level of import dependence in the Nigerian economy. In any case, the exchange rate variable follows the expected negative sign, industrial output, sectoral loans and advances to the agricultural sector all follow expected signs both in the short and long-run analysis, except government expenditure to the agricultural sector that is negative and insignificant in the long-run and positive in the normalized co-integration model.

\section{Conclusion}


The primary aim of this study is to investigate the relationship between agriculture and manufacturing industry output, to enable policy makers understand the linkage that facilitate the direction of investment and policy implementation. The empirical analysis employed a co-integration and Johansen error correction specification on a time series data for macroeconomic variables, which includes inflation and exchange rate, government recurrent expenditure on the agricultural sector and sectorial commercial bank loans for the period 1982 to 2015 to explain the variation in agricultural output. Results from the Granger Causality test indicate a bidirectional relationship between agriculture and manufacturing industry output, which implies backward and forward linkages in the input-output interface. This two-way linkage implies that government investment in the agricultural sector equally boost manufacturing output and vice versa. An increasing output from the manufacturing industry will invariably cause an increase in agricultural productivity.

A bidirectional positive relationship between agriculture and manufacturing industry output is subject to the condition that other explanatory variables are held constant. However, that will never be the case, in the face of existing realities, the long-run vector error correction model with a positive coefficient implies a divergence from equilibrium. To restore stability in the long-run behavior of explanatory variables, there is a need for macroeconomic balance. The macroeconomic variable - inflation, which increases the cost of input for agriculture also hampers the demand for manufacturing industry output. When there is rising prices, the demand for manufacturing industry output will fall especially in the face of high cost of imported equipment for use in manufacturing industries due to devaluation of the local currency and the resulting higher exchange rates. Another major problem that would have caused the divergence is the paucity of long-term data for analysis to provide the necessary platform for the control of seasonal and cyclical variations in a time series.

A major policy implication arising from this study is the need for increased government investment in the agricultural sector to boost yield, with counterfactual support to the manufacturing industry, so that the necessary inputs to boost agriculture could be obtained at minimum cost and agricultural productivity rising to provide necessary input for manufacturing industry output. A recommendation for further research is understanding temporal constraints and omitted variable bias, which this study tactfully overlooked due to analytical techniques employed. Secondly, a further study into the growth of capital-labor ratio of agricultural productivity with respect to manufacturing industry output will provide the necessary information for sustainable investment in agriculture and agro-based manufacturing.

\section{References:}

Acemoglu, Daron and James Robinson (2012). "Why Nations Fail,” Crown Publishers New York

Ahungwa, G. T., Haruna, U., and Abdusalam, R., (2014). Trend analysis of the contribution of agriculture to the gross domestic product of Nigeria $(1960-2012)$. IOSR Journal of Agricultural and Veterinary Science, Vol. 7, Issue 1, Ver. IV (Feb. 2014), pp. 50-55.

Bhagwati, J., and Srnivasan, T. N., (2002). Trade and poverty in the poor countries, American Economic Review, May 2002. 
Chebbi, H. E., and Lachaal, L. (2007). "Agricultural Sector and Economic Growth in Tunisia: Evidence from Cointegration and Error Correction Mechanism", Paper presented at the $103^{\text {rd }}$ EAAE Seminar Adding Value to the Agro-Food Supply Chain in the Future EuroMediterranean Space, held in Barcelona, Spain on 23-25 April 2007.

de Souza, Joao Paulo A. (2015). Evidence of growth complementarity between agriculture and industry in developing countries. Structural Change and Economic Dynamics 34, 1-18.

Desai, Raj M., and Rudra, Nita (2018). Trade, poverty, and social protection in developing countries. European Journal of Political Economy, 20 August 2018.

Diao, X., McMillan, M., and Wangwe, S., (2018). Agricultural labour productivity and industrialization lessons for Africa. Journal of African Economies, 27(1). 28-65

Ekpo, A.H. and Umoh, O.J. (2012) Overview of the Nigerian Economic Growth and Development.

Fuglie, K., and Rada, N., (2013). Resources, policies, and agricultural productivity in sub-Saharan Africa. United States Department of Agriculture, Economic Research Report No. (ERR-145) 78 pp February.

Granger, C. (1969). Investigating Causal Relations by Econometric Models and Cross-Spectral Methods. Econometrica, Volume 37, Issue 3 (Aug).

Granger, C. and P. Newbold (1974), "Spurious Regressions in Econometrics." Journal of Econometrics, 2, pp. 111-120.

Gemmel, N., Lloyd, T. A., and Mathew, M. (2000). "Agricultural Growth and Inter-Sectoral Linkages in a Developing Economy”, Journal of Agricultural Economics, vol. 51. no. 3, pp.353-370.

Gujarati. (2004). Basic Econometrics. The Mc-Graw Hills company.

Hirschman, Albert O. (1958). The Strategy of Economic Development. New Haven, Conn.: Yale University Press.

IFAD. (2012). Food Security Portal. Retrieved from IFPRI Website: http://www.foodsecurityportal.org/nigeria

Johansen, 1988. Statistical Analysis of Cointegrating Vectors. Journal of Economic Dynamics and Control, Vol. 12, pp.231-254.

Johansen, Søren (1991). "Estimation and Hypothesis Testing of Cointegration Vectors in Gaussian Vector Autoregressive Models". Econometrica 59 (6): 1551-1580.

Kanwar, S. (2000). "Does the Dog Wag the Tail or the Tail the Dog? Cointegration of Indian Agriculture with Non-agriculture", Journal of Policy Modeling, vol. 22, no. 5, pp. 533-556.

Koo, Won Wi, and Jianquang Lou, (1997). "The relationship between the agricultural and industrial sectors in Chinese economic development." Department of Agricultural Economics, North Dakota State University, Fargo, ND 58105 - 5636. 
Lin, Jinding, and Won W. Koo (1990). "Economic Development in the Agricultural and Industrial Sectors in the People's Republic of China." Ag. Econ. Rpt. No. 263, Dept. of Ag. Econ., North Dakota State University, Fargo, 1990.

Manyong VM, Ikpi A, Olayemi JK, Yusuf SA, Omonona BT, Okoruwa V, Idachaba FS (2005). Agriculture in Nigeria: Identifying Opportunities for Increased Commercialization and Investment. IITA, Ibadan, Nigeria. p. 159.

Matthew A, O., \& Azuh, D. (2011). The Role of Agriculture in Poverty Alleviation and National Development in Nigeria. 1-20.

Ogundari, K., \& Awokuse, T. (2016). Assessing the Contribution of Agricultural Productivity to Food Security levels in Sub-Saharan African countries. Agricultural \& Applied Economics Association Annual Meeting, 1-26.

Omorogiuwa, Omorogbe., Jelena Zivkovic and Fatima Ademoh (2014). "The role of agriculture in the economic development of Nigeria". European Scientific Journal, Vol. 10, No. 4.

O'Ryani, R., and Miller, S., (2003). The role of agriculture in poverty alleviation, income distribution and economic development: a CGE analysis for Chile. Agricultural and Development Economics Division, Food and Agriculture Organization of the United Nations: The roles of agriculture international conference, Rome Italy, October.

Osabohien, R. and Osuagwu, E., (2017). Social protection policies and agricultural output in Nigeria: Empirical investigation using household survey data. Presented at the 4th Covenant University International Conference on E-Governance in Nigeria (CUCEN), Covenant University, Ota, Nigeria, 7-9 May 2017.

Osuagwu, E S., and Olaifa, E., (2018). Effects of oil spills on fish production in the Niger Delta. PLoS ONE 13(10). http://doi.org/10.1371/journal.pone.0205114

Saikia, D. (2009). Agriculture-Industry Interlinkages: Some Theoretical and Methodological Issues in the Indian Context. Munich Personal RePEc Archive, 1-32.

Subramaniam, V., \& Reed, M. (2009). Agricultural Inter-Sectoral Linkages and Its Contribution to Economic Growth in the Transition Countries. International Association of Agricultural Economists Conference, Beijing, China, (pp. 1-22). China.

Takahiro, F., Mayumi, M., \& Tatsufumi, Y. (2006). Industrialization and poverty alleviation: propoor industrialization strategies revisited. Japan: United Nations Industrial Development Organisation.

Tiffin, R. and Irz, X. (2006). "Is Agriculture the Engine of Growth?" Agricultural Economics 35 (1): $79-89$.

Zeira, J., and Hosny Zoabi, (2015). Economic growth and sector dynamics. European Economic Review 79, 1 - 15 . 
